\title{
Different accounting approaches to harvested wood products (HWP) in a local greenhouse gas inventory
}

\author{
S. Bastianoni, S. Bosco \& S. Focardi \\ Department of Chemistry, University of Siena, Italy
}

\begin{abstract}
At present there are several different approaches for reporting the storage of carbon in wood products and its possible subsequent release as $\mathrm{CO}_{2}$. The 2006 IPCC Guidelines for National Greenhouse Gas Inventories allow one to choose four different accounting approaches to harvested wood products (HWP). Indeed, there is no international agreement on the methods to be used in national greenhouse gas emission inventories yet. These approaches differ by the criterion adopted for the allocation of the emissions derived from the carbon stock loss with the harvest from the nation where the wood is harvested and the nation where the wood is utilized and for the wood use. Therefore, reported national carbon emissions differ according to the accounting approach used, and the implications of each accounting approach vary for different countries. HWP become a very sensitive emissions category when the greenhouse gas inventory is applied to a local territorial system, if the volume of HWP exchanged is relevant.

This paper investigates two different accounting approaches for fuel wood applied to the Greenhouse Gas Inventory of Siena Province, Italy, developed for the year 2006. The first approach follows Tier 1 of the 2006 IPCC methodologies subtracting the entire HWP carbon content in the inventory year. In the second approach we try to allocate the carbon loss with the HWP according to the actual use and users. The aim of this paper is to determine whether different approaches provide distinctive incentives to reach major policy goals related to climate.
\end{abstract}

Keywords: emission allocation, IPCC, wood use, carbon stock loss, local system. 


\section{Introduction}

Harvested wood brought from a forest ecosystem into human society passes through phases of manufacture, use, and disposal. HWP includes all wood material (including bark) that leaves harvest sites. Some of this wood accumulates in society as wood products and wastes, and some decomposes and releases carbon into the atmosphere. Therefore, in addition to forest ecosystems, human society creates a carbon pool through its use and disposal of harvested wood products (HWP) [1].

Worldwide - according to a study by Winjum et al. [2] and a report by the UNFCCC secretariat [3] - the amount of carbon held in harvested wood products is likely to be increasing.

The time carbon is held in products vary depending on the product and its uses. For example, fuelwood and mill residue may be burned in the year of harvest; many types of paper are likely to have a life in uses less than 5 years which may include recycling of paper; and sawnwood or panels used in buildings may be held for decades to over 100 years [4].

The 1996 IPCC Guidelines [5] did not provide methods for estimating carbon held in HWP, and recommended, for the purpose of basic calculations, a default assumption expressed as "... all carbon biomass harvested is oxidized in the removal [harvest] year". This was based on the perception that HWP stocks are not changing.

Currently there are several different approaches for reporting the storage of carbon in wood products and its subsequent release as $\mathrm{CO}_{2}$. The 2006 IPCC Guidelines for National Greenhouse Gas Inventories allow choosing four different accounting approaches to harvested wood products (HWP). The alternative approaches to estimate and report the contribution of HWP to annual AFOLU (Agriculture, Forestry and Other Land Uses) $\mathrm{CO}_{2}$ emissions/removals differ in how they allocate the HWP between wood producing and consuming countries, and what processes (atmospheric fluxes or stock changes) they focus on.

The 2006 IPCC Guidelines for National GHG Inventories [4] provide four accounting approaches to HWP: the stock-change approach, the atmosphericflow approach, the production approach, and the simple decay approach. These differ in the way they define system boundaries. Therefore, reported national carbon emissions differ according to the accounting approach used [2, 6-9]. To avoid either double counting or exclusion of emissions, the same approach should be applied at the same time in all countries. However, the implications of each accounting approach differ for different countries.

The majority of the methods proposed investigate the gradual emissions in time of enduring wood products. In this paper we focus the attention on the importance of fuel wood accounting method. In the IPCC Guidelines, both 1996 and 2006, all the carbon losses as wood harvested for fuel wood is considered used up in the same year of the harvest, considering the carbon loss totally charged to the place of harvest. There is no consideration on where this fuel wood is actually used, and how. 
We considered different accounting hypothesis referring to a key study of a local system in central Italy, the Siena Province. The administration of this area has determined to control and monitor the greenhouse gas emissions in respect to the Kyoto Protocol goals, certifying the emission estimate according to the ISO 14064 standard. The ISO 14064 provides governments and industries with an integrated set of tools for programs aimed at reducing greenhouse gas emissions, as well as for emissions trading.

The aim of this paper is to determine whether different approaches provide incentives to reach major policy goals related to climate and forest management, taking into account the effects for wood use change.

\section{Materials and methods}

The Siena Province greenhouse gas inventory has been elaborated on the basis of the 2006 IPCC Guidelines for National GHG Inventories [4]. The criterion of the IPCC method is geographical. In other words, all emissions of an activity occurring within a region's boundaries are accounted for. However, emission produced by a region may be calculated considering not only those actually generated in the region but also those generated anywhere outside it, if related to the activities occurring in the region. Thus the geographical principle is, at least in part, replaced by a responsibility principle that involves considerations of all emissions derived from the final use of energy attributed to an activity in the region, whether produced within or outside the region. Clearly, the bigger the region, the more similar the results obtained through the different methods of calculation, up to the national scale.

The IPCC method was calibrated for the national scale where the Kyoto obligations to reduce greenhouse gas emissions must be met. If the method is used at a smaller scale (state, county, municipality), a mixed criterion based both on geographic and responsibility may be more appropriate, since as scale reduces, exchanges with outside increase with respect to those within the system, and a geographical criterion alone may lead to overestimations or underestimations.

Regarding the HWP emissions accounting, two scenarios have been elaborated based the first on the IPCC basic criterion and the second on the responsibility of the final consumer. It has not been possible to estimate a precise import - export flux for the provincial scale. Tuscany is the forth region in Italy for fuelwood exportation towards the rest of Italy, due to the large extension of coppice oak forests, that constitute the $80 \%$ of the total forest land. Therefore in the second scenario it has been assumed that imports of fuelwood and stock change are equal to zero; only the exportation out of province borders has been considered.

\section{Results}

Analyzing the greenhouse gas emissions and removals of the Siena province emerged the role of fuel wood products. Tuscany produces the $25 \%$ of the total 
national fuel wood, consuming only a fraction on its territory. In the Siena province this means that the consumption reach only the $20 \%$ of the fuel wood production from broad leaved species (Table 1), according to the estimates of the provincial Forest Service.

The greenhouse gas inventory has been elaborated for the Siena province per the year 2006 for all the IPCC sectors. The AFOLU sector reaches the $11 \%$ of the total gross emission, with the nitrous oxide emissions from nitrogen addiction to soil as the principal category. Starting from the harvested wood data from the Forestal Corp the carbon loss with the harvest has been estimated for the two scenarios. In Table 2 the main emissions categories have been shown, with the percent on the total gross emissions.

The carbon loss from biomass in the scenarios reaches $8,4 \%$ and $2 \%$ of the total emissions, respectively, with the harvest covering $97 \%$ and $86 \%$ of the biomass carbon loss. In Table 3 the total carbon balance of forest and cropland biomass is presented.

Table 1: $\quad$ Fuel wood production in Siena province in 2006.

\begin{tabular}{|l|r|c|}
\hline & \multicolumn{1}{|c|}{ Biomass removed } & Local consumption \\
\hline & $\mathrm{t}$ & \\
\hline Broad-leaved & 145,249 & $20 \%$ \\
\hline Conifer & 3,442 & $0 \%$ \\
\hline Total biomass & 148,691 & \\
\hline
\end{tabular}

Table 2: $\quad$ Greenhouse gas emissions for main categories.

\begin{tabular}{|l|r|r|r|r|}
\hline & \multicolumn{2}{|c|}{ Scenario I } & \multicolumn{2}{c|}{ Scenario II } \\
\hline Activity & $\mathrm{t} \mathrm{CO}_{2 \mathrm{eq}}$ & \multicolumn{1}{c|}{$\%$} & \multicolumn{1}{c|}{$\mathrm{CO}_{2 \mathrm{eq}}$} & \multicolumn{1}{c|}{$\%$} \\
\hline Energy & $1,284,656$ & 75.2 & $1,284,656$ & \multicolumn{1}{c|}{80.4} \\
\hline Transport & 740,877 & 43.3 & 740,877 & 46.4 \\
\hline Residential & 438,130 & 25.6 & 438,130 & 27.4 \\
\hline Commercial & 44,598 & 2.6 & 44,598 & 2.8 \\
\hline Electricity & 61,050 & 3.6 & 61,050 & 3.8 \\
\hline Industrial processes & 11,973 & 0.7 & 11,973 & 0.7 \\
\hline Waste & 125,475 & 7.3 & 125,475 & 7.9 \\
\hline Landfill & 109,978 & 6.4 & 109,978 & 6.9 \\
\hline Waste water & 13,974 & 0.8 & 13,974 & 0.9 \\
\hline Composting & 1,522 & 0.1 & 1,522 & 0.1 \\
\hline AFOLU & 286,991 & 16.8 & 175,316 & 11.0 \\
\hline C loss & 143,221 & 8.4 & 31,546 & 2.0 \\
\hline Urea use & 5,040 & 0.3 & 5,040 & 0.3 \\
\hline Enteric fermentation & 47,167 & 2.8 & 47,167 & 3.0 \\
\hline Manure management & 18,177 & 1.1 & 18,177 & 1.1 \\
\hline N addition to soil & 73,385 & 4.3 & 73,385 & 4.6 \\
\hline Total gross emissions & $1,709,094$ & 100 & $1,597,418$ & 100 \\
\hline
\end{tabular}


Table 3: Balance of the carbon in biomass for the two scenarios.

\begin{tabular}{|c|c|c|}
\hline & SCENARIO I & SCENARIO II \\
\hline \multirow[t]{2}{*}{ Carbon Gain } & $\Delta \mathbf{C}_{\mathrm{G}}$ & $\Delta \mathbf{C}_{\mathrm{G}}$ \\
\hline & t C (year) $)^{-1}$ & $\mathrm{tC}(\text { year })^{-1}$ \\
\hline Forest absorption & 307,549 & 307,549 \\
\hline Cropland absorption & 4,107 & 4,107 \\
\hline Total Gain & 311,656 & 311,656 \\
\hline \multirow[t]{2}{*}{ Carbon Loss } & $\Delta \mathrm{C}_{\mathrm{L}}$ & $\Delta \mathrm{C}_{\mathrm{L}}$ \\
\hline & $\mathrm{tC}$ (year) ${ }^{-1}$ & $\mathrm{tC}$ (year) $^{-1}$ \\
\hline Biomass loss for fire & 1,196 & 1,196 \\
\hline Wood removed & 37,865 & 7,408 \\
\hline Total Loss & 39,060 & 8,603 \\
\hline \multirow{5}{*}{$\begin{array}{l}\text { Annual variation } \\
\text { in carbon biomass stock }\end{array}$} & $\Delta \mathrm{C}_{\mathrm{B}}$ & $\Delta C_{B}$ \\
\hline & t C (year) $)^{-1}$ & t C (year) $)^{-1}$ \\
\hline & 272,595 & 303,052 \\
\hline & $\mathrm{t} \mathrm{CO}_{2}(\text { year })^{-1}$ & $\mathrm{t} \mathrm{CO}_{2}$ (year) $)^{-1}$ \\
\hline & $-999,517$ & $-1,111,192$ \\
\hline
\end{tabular}

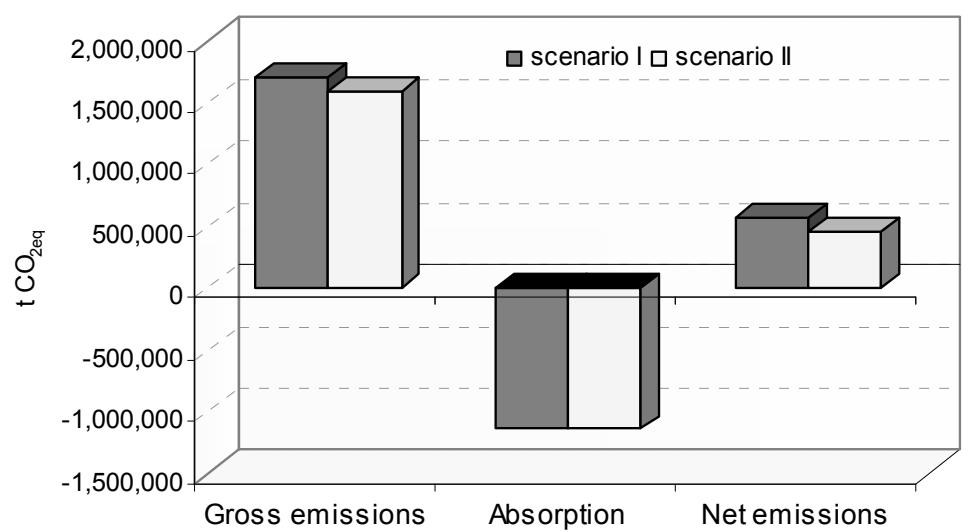

Figure 1: Greenhouse gas balance for Siena province according to the proposed scenarios.

This important difference in carbon balance involves a meaningful variation in the final greenhouse gas balance, presented in Figure 1. The net emissions pass from $566,356 \mathrm{t} \mathrm{CO}_{2 \mathrm{eq}}$ (scenario I) to $454,680 \mathrm{t} \mathrm{CO}_{2 \mathrm{eq}}$ (scenario II). This difference is equivalent to a variation from $67 \%$ to $72 \%$ in the total absorption of the gross emissions.

In attempt to combining the two scenarios proposed, we can hypothesize a different use for fuel wood. If the fuel wood remain within the province border, we can assume to use it e.g. in the residential heating, converting the boilers feed with natural gas or diesel oil in boilers feed with wood pellets. The use of fuel wood in residential heating can substitute the $17.8 \%(1,339,940 \mathrm{GJ})$ of the total 
consumption these categories $(7,530,625 \mathrm{GJ})$, in this way $77,865 \mathrm{t} \mathrm{CO}_{2}$ can be avoided to be emitted, moving the absorption from $67 \%$ to $70 \%$ in the scenario I.

It is important to note that with the Scenario II approach the fuel wood assumes a higher importance: it is not carbon neutral to burn fuel wood acquired from outside the system. This would eliminate the problem of an inefficient use of the wood, since now, considering it as not emitting $\mathrm{CO}_{2}$, it can be used regardless of the actual outcome.

\section{Conclusion}

In this paper we analyzed the importance of fuel wood accounting method, considered in the IPCC methodology as if all the carbon loss with wood harvested for fuel wood were used up in the same year of the harvest, considering the carbon loss totally charge to the place of harvest. We elaborated two scenarios, in the first we follow the IPCC default methodology, in the second we proposed, for this important emissions categories, to attribute the responsibility to the final consumer. In this way the geographical approach followed by IPCC satisfies also a consumption criterion and it may have a positive effect in reducing the greenhouse gas emissions, promoting the use of a renewable and local available energy, as fuel wood.

\section{References}

[1] Hashimoto, S., Different accounting approaches to harvested wood products in national greenhouse gas inventories: their incentives to achievement of major policy goal. Environmental Science \& Policy, 11, pp 756-771, 2008.

[2] Winjum, J.K., Brown, S., Schlamadinger, B., Forest harvests and wood products: sources and sinks of atmospheric carbon dioxide. Forest Science, 44, pp 272-284, 1998.

[3] IPCC. Good Practice Guidance for Land Use, Land-Use Change and Forestry. IPCC National Greenhouse Gas Inventories Programme, Technical Support Unit. IGES, Hayama, Kanagawa, Japan, 2003.

[4] IPCC. 2006 IPCC Guidelines for National Greenhouse Gas Inventories, Prepared by the National Greenhouse Gas Inventories Programme, Eggleston H.S., Buendia L., Miwa K., Ngara T. and Tanabe K. (eds). Published: IGES, Japan, 2006.

[5] IPCC. Revised 1996 IPCC guidelines for national greenhouse gas inventories. Bracknell: Intergovernmental Panel on Climate Change. WG I Technical Support Unit. 1997.

[6] Hashimoto, S., Nose, M., Obara, T., Moriguchi, Y., Wood products: potential carbon sequestration and impact on net carbon emissions of industrialized countries. Environmental Science and Policy, 5, pp 183-193. 2002.

[7] Pingoud, K., Perala, A.-L., Soimakallio, S., Pussinen, A., Greenhouse gas impacts of harvested wood products: evaluation and development of 
methods. VTT Research Notes 2189. VTT Information Service, Finland. 2003.

[8] Green, C., Avitabile, V., Farrell, E.P., Byrne, K.A., Reporting harvested wood products in national greenhouse gas inventories: implications for Ireland. Biomass and Bioenergy, 30, pp 105-114. 2006.

[9] Dias, A.C., Louro, M., Arroja, L., Capela, I., Carbon estimation in harvested wood products using country specific method: Portugal as a case study. Environmental Science and Policy, 10, pp 250-259. 2007.

[10] Bastianoni S., Pulselli F.M., Tiezzi, E. The problem of assigning responsibility for greenhouse gas emissions. Ecological Economics, 49(3), pp 253-257. 2004. 